\title{
Synthesis of gold nanoparticles stabilised by metal-chelator and the controlled formation of close-packed aggregates by them ${ }^{\text {II }}$
}

\author{
SANTANU BHATTACHARYA ${ }^{\dagger} *$ and AASHEESH SRIVASTAVA \\ Department of Organic Chemistry, Indian Institute of Science, \\ Bangalore 560 012, India \\ ${ }^{\dagger}$ Also at Chemical Biology Unit, Jawaharlal Nehru Centre for Advanced \\ Scientific Research, Jakkur Campus, Jakkur PO, Bangalore 560 064, India \\ e-mail: sb@orgchem.iisc.ernet.in
}

\begin{abstract}
Nanoparticles have properties that can be fine-tuned by their size as well as shape. Hence, there is significant current interest in preparing nano-materials of small size dispersity and to arrange them in close-packed aggregates. This manuscript describes ways of synthesising gold nanoparticles using a metal-chelator derivative $\mathbf{1}$, as stabiliser. Controlled synthesis conditions lead to formation of nanoparticles thereby indicating the ability of $\mathbf{1}$ to act as efficient stabiliser. The nanoparticles formed were characterised by transmission electron microscopy and UV-Vis spectroscopy. TEM analysis showed the formation of dense aggregates of nanoparticles. This can be ascribed to the inter-particle hydrogen bonding possible by the carboxylic acid moiety of $\mathbf{1}$ that leads to aggregation. The aggregation can be controlled by the $\mathrm{pH}$ of the solution employed for dispersing the particles.
\end{abstract}

Keywords. Gold nanoparticles; synthesis; metal chelator; hydrogen bonding; aggregate.

\section{Introduction}

Nanoparticles attract greater attention today due to the various applications they have in different fields. ${ }^{1}$ These systems are characterised by having one of their dimensions in nanometre range. This size regime is of great importance since it is in the 'nano-regime' that properties of materials can be tuned by varying the size. ${ }^{2,3}$ The properties of these materials are in-between that of individual molecule and bulk material. Changing the size of material can conveniently vary these. Gold nanoparticles are known for their beautiful wine-red colouration and are known to have one of the highest extinction coefficients known (of the order of $10^{9} \mathrm{M}^{-1} \mathrm{dm}^{-1}$ ). ${ }^{4}$ The bright colour of nanoparticles is ascribed to the transverse oscillations of the surface electrons of the particle on interaction with light of suitable wavelength, the surface plasmon resonance. It has also been shown that the surface plasmon band is greatly dependent on the nanoparticle size. ${ }^{5}$ Shape of the nanoparticle also plays an important role in deciding the position of this band. In case of gold nanorods, for example, it shifts to the near infra-red region of around $850 \mathrm{~nm} .{ }^{6}$ Now methods are available to synthesize nanoparticles that are remarkably stable for many cycles of drying and redissolution. ${ }^{7}$ Size-control was achieved by varying the Au (III)/ thiol ratio, wherein the greater the amount of thiol used, smaller was the particle size

\footnotetext{
IDedicated to Professor C N R Rao on his 70th birthday

*For correspondence
} 
formed. ${ }^{8,9}$ We have shown that the size of the synthesised nanoparticles can also be finetuned by the bulkiness of the thiol used. ${ }^{10}$ Thus, single-chain stabiliser gave the largest average particle diameter; double-chain stabiliser gave smaller nanoparticles while double-chain stabiliser with a bulky cholesterol group gave the smallest particles. The ability to tune the properties of nanomaterials by changing their shapes and size makes it imperative to have methods of making nanoparticles of different shapes. There have been reports of using polymers to achieve this aim. ${ }^{11}$ It was also shown that use of some surfactants along with 'seeds' (small nanoparticles on which growth occurs) during nanoparticle synthesis causes the formation of materials of different shapes. ${ }^{12}$ The surfactant molecules form reverse micelle that, after a particular concentration, assemble into inverted hexagonal networks. It is these assemblies that act as templates during the nanomaterial synthesis and help in formation of material in shape-controlled fashion. ${ }^{13}$

The surface plasmon band of nanoparticles is very sensitive not only to their size and shape but also to the inter-particle distance. In aggregated state, the individual nanoparticles can interact with each another and give rise to oscillations that are combinations of oscillations of individual nanoparticles. ${ }^{14}$ This causes red shift in the surface plasmon band on aggregation. This type of colour change on aggregation has been extensively used in sensing different analytes. Gold nanoparticles modified with oligonucleotides were a shown to be efficient system for colorimetric detection of single nucleotide mismatches in DNA. ${ }^{15}$ Similarly, crown-ether-functionalised nanoparticles showed selective sensing of $\mathrm{K}^{+}$ions. ${ }^{16} \mathrm{We}$ attempted the preparation of nanoparticles with metal chelator to study the sensing properties. This article reports the initial results of nanoparticles preparation using the metal-chelator containing molecule $\mathbf{1}$ and the $\mathrm{pH}$-controlled formation of macroscopic aggregates by them.

\section{Materials and methods}

Hydrogen tetrachloroacurate trihydrate $\left(\mathrm{HAuCl}_{4} \cdot 3 \mathrm{H}_{2} \mathrm{O}\right)$, sodium borohydride $\left(\mathrm{NaBH}_{4}\right)$ and potassium thioacetate $\left(\mathrm{CH}_{3} \mathrm{COSK}\right)$ were purchased from Aldrich Chemical Co. and used as received. Methanol was distilled prior to use. Water used was distilled twice over $\mathrm{KMnO}_{4}$ to remove organic impurities. Glacial acetic acid was from Ranbaxy Chemicals. Hydrochloric acid was from SD Fine Chemicals.

\subsection{Synthesis of $\mathbf{1}$}

The stabilising agent, $\mathbf{1}$, containing the iminodiacetic acid moiety was synthesised as shown in scheme 1 .

2.1a Methyl iminodiacetate (1a): Iminodiacetic acid (1 g, $7.5 \mathrm{mmol})$ and methanol (15 ml, excess) were taken in a round-bottom flask and 10 drops of conc. $\mathrm{H}_{2} \mathrm{SO}_{4}$ was added. Iminodiacetic acid slowly dissolved on stirring. This was then refluxed for $8 \mathrm{~h}$. After this, methanol was removed and the reaction mixture neutralised by saturated $\mathrm{NaHCO}_{3}$ and extracted three times in chloroform $(3 \times 25 \mathrm{ml})$. TLC showed a single spot in $1: 2$ ethyl acetate/hexanes. Evaporation of the solvent yielded $1.15 \mathrm{~g}$ oil (90\% yield). ${ }^{1} \mathrm{H}-\mathrm{NMR}\left(\mathrm{CDCl}_{3}, 300 \mathrm{MHz}\right) \ddot{a} \mathrm{ppm}: 1.88(b r, 1 \mathrm{H}, \underline{\mathrm{HN}}), 3.55\left(s, 4 \mathrm{H},\left(\underline{\mathrm{C}}_{2}\right)_{2} \mathrm{~N}\right), 3.71(s$, $\left.6 \mathrm{H},\left(\mathrm{COOC} \underline{\mathrm{H}}_{3}\right)_{2}\right)$. FTIR (neat) $\left[\mathrm{cm}^{-1}\right] 3320,2918,2852,1746$. 


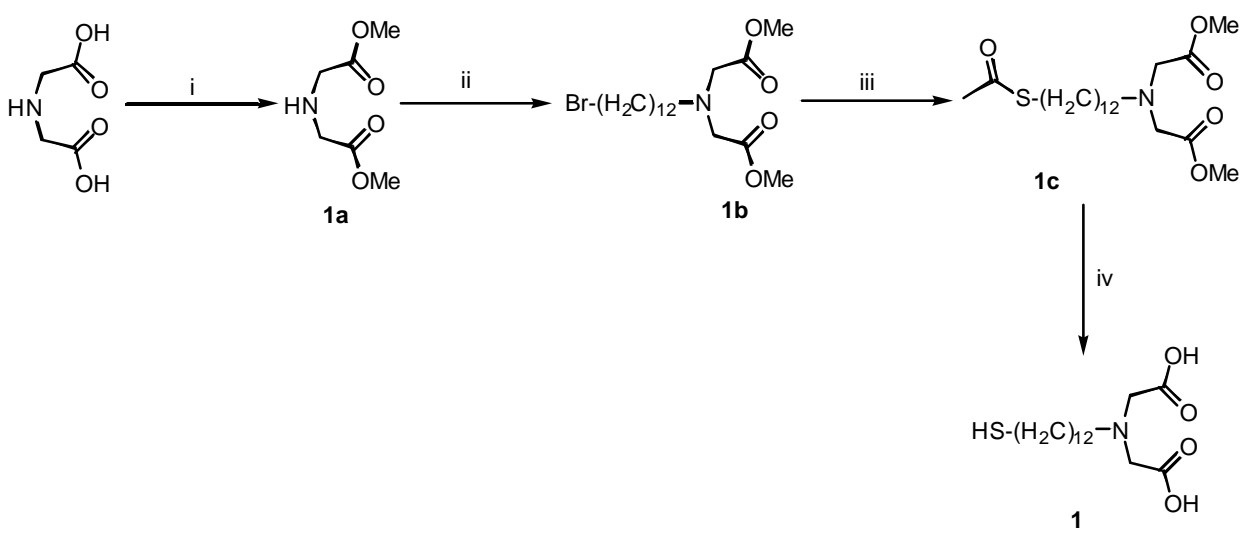

Reagents and conditions: (i) dry $\mathrm{MeOH}$, c. $\mathrm{H}_{2} \mathrm{SO}_{4}, 8 \mathrm{~h}$ reflux, (ii) 1,12-dibromo-dodecane (3 equiv.), dry acetone, anhydrous $\mathrm{K}_{2} \mathrm{CO}_{3}, 30 \mathrm{~h}$ reflux, (iii) $\mathrm{CH}_{3} \mathrm{COS}^{-} \mathrm{K}^{+}$, dry DMF, stir RT $6 \mathrm{~h}$, (iv) $\mathrm{NaOH}, 6 \mathrm{~h}$ reflux; $\mathrm{HCl}, 0^{\circ} \mathrm{C}$.

Scheme 1. Synthesis scheme for the metal-chelator-containing stabiliser 1.

2.1b 12-Bromododecyl-1-methyliminodiacetate (1b): Methyl iminodiacetate (200 mg, $1.3 \mathrm{mmol})$ and 1,12-dibromododecane $(1 \mathrm{~g}, 3.1 \mathrm{mmol})$ were refluxed together in the presence of $\mathrm{K}_{2} \mathrm{CO}_{3}$ using dry acetone $(7 \mathrm{ml})$ as solvent. After $30 \mathrm{~h}$, the reaction mixture showed the absence of methyl iminodiacetate. The solvent was removed and the reaction mixture was extracted in chloroform. The chloroform layer was washed with water to remove the excess $\mathrm{K}_{2} \mathrm{CO}_{3}$. Chloroform layer was concentrated and column chromatographed on 60-120 mesh silica gel. 8\% Ethyl acetate in hexanes was used as the eluent mixture to isolate $320 \mathrm{mg}$ of the desired compound as oil. Isolated yield was $63 \% .{ }^{1} \mathrm{H}$ NMR $\left(\mathrm{CDCl}_{3}, 300 \mathrm{MHz}\right) \ddot{a}$ ppm: 0.8-1.8 (br m, 18H, $\left.\left(\mathrm{C}_{2}\right)_{9}\right), 2.67\left(t, 2 \mathrm{H}, \mathrm{Br} \mathrm{CH}_{2} \mathrm{CH}_{2}\right)$, $3.40\left(t, 2 \mathrm{H}, \mathrm{BrC}_{2}\right), 3.53\left(s, 4 \mathrm{H},\left(\mathrm{C}_{2}\right)_{2} \mathrm{~N}\right), 3.71\left(s, 6 \mathrm{H},\left(\mathrm{COOC} \underline{\mathrm{H}}_{3}\right)_{2}\right)$. FTIR (neat) [cm ${ }^{-1}$ ] 2927, 2854, 1752, 1462, 1433, 1352, 1198, 1175, 1015, 877, 721. EI-MS = $327\left(M^{+}-\mathrm{Br}\right)$.

2.1c 12-Thioacetyldodecyl-1-methyliminodiacetate (1c): 12-Bromododecyl-1-methyliminodiacetate $(380 \mathrm{mg}, 0.85 \mathrm{mmol})$ was dissolved in dry DMF $(5 \mathrm{ml})$. To this was added with stirring potassium thioacetate $(114 \mathrm{mg}, 1 \mathrm{mmol})$. As soon as potassium thioacetate dissolved, white coloured precipitate started appearing. This was stirred for $6 \mathrm{~h}$ at room temperature. TLC showed complete conversion of $\mathbf{1 b}$. This mixture was then concentrated in vacuum pump and extracted in dichloromethane. It was then column-chromatographed over silica gel (60-120 mesh) using $12 \%$ ethylacetate in hexanes to isolate pure product as oil $\left(260 \mathrm{mg}, 70 \%\right.$ isolated yield). ${ }^{1} \mathrm{H}-\mathrm{NMR}\left(\mathrm{CDCl}_{3}, 300 \mathrm{MHz}\right) \ddot{a} \mathrm{ppm}: 0.8-1.6$ (br m, 18H, $\left.\left(\mathrm{C}_{2}\right)_{9}\right), 2.32$ ( $\left.s, 3 \mathrm{H}, \mathrm{C}_{3} \mathrm{COS}\right), 2.67\left(t, 2 \mathrm{H}, \mathrm{BrCH}_{2} \mathrm{C}_{2}\right), 2.86(t, 2 \mathrm{H}$, $\left.\mathrm{CH}_{3} \mathrm{COSC}_{2}\right), 3.53\left(s, 4 \mathrm{H},\left(\mathrm{C}_{2}\right)_{2} \mathrm{~N}\right), 3.71\left(s, 6 \mathrm{H},\left(\mathrm{COOC} \underline{H}_{3}\right)_{2}\right)$. FTIR (neat) [cm ${ }^{-1}$ ] 2927, 2854, 1752, 1744, 1693, 1462, 1433, 1353, 1198, 1134, 1175, 1015, 877, 721. EI$\mathrm{MS}=302\left(M^{+}-\mathrm{COOMe}-\mathrm{CH}_{3} \mathrm{CO}\right)$.

2.1d 12-Mercaptododecyl-1-iminodiacetic acid (1): The thioacetate compound 1c (250 mg, $0.62 \mathrm{mmol}$ ) was dissolved in $\mathrm{MeOH}$ and to this was added $1 \mathrm{ml}$ of $(3 \mathrm{M})$ aqueous $\mathrm{NaOH}$ solution. This mixture was then refluxed for $6 \mathrm{~h}$ to ensure complete 
cleavage of the acetate protection of the thiol moiety as well as the methyl ester. After 6 $\mathrm{h}$, the mixture was gradually cooled to $\sim 0^{\circ} \mathrm{C}$ and then $1 \mathrm{M} \mathrm{HCl}$ was added to neutralize the excess $\mathrm{NaOH}$. This led to the formation of a white precipitate. The mixture was filtered using a sintered glass crucible and the precipitate was vacuum-dried over $\mathrm{P}_{2} \mathrm{O}_{5}$ overnight to isolate $110 \mathrm{mg}$ of product. Yield $=53 \%$. EI-MS $=288\left(M^{+}-\mathrm{COOH}\right)$. Elemental analysis: Calcd. for $\mathrm{C}_{16} \mathrm{H}_{31} \mathrm{NO}_{4} \mathrm{~S} ; \mathrm{C}=57.625 \mathrm{H}=9.369 \mathrm{~N}=4.200 \%$, Found: $\mathrm{C}=57.43 \mathrm{H}=9.41 \mathrm{~N}=3.9 \%$. FTIR $(\mathrm{KBr})\left[\mathrm{cm}^{-1}\right]$ 3438, 2921, 2851, 1730, 1585, 1467, $1431,1376,1254,1058,958,900,720$.

\subsection{Synthesis of nanoparticles}

Gold nanoparticle synthesis was undertaken after complete characterization of the stabilizer molecule. $\mathrm{HAuCl}_{4} \cdot 3 \mathrm{H}_{2} \mathrm{O}(5 \mathrm{mg})$ was dissolved in $\mathrm{MeOH}$. To this was added $5 \mathrm{mg}$ of 1 and the mixture was bath-sonicated for $5 \mathrm{~min}$ to ensure proper mixing of $\mathrm{Au}$ and 1. Reduction of $\mathrm{Au}(\mathrm{III})$ to $\mathrm{Au}(0)$ was done by using 15 -fold excess of $\mathrm{NaBH}_{4}{ }^{17}$ Immediate colour change was observed from bright yellow to red. Visible precipitation was observed within a minute of addition of reducing agent. The precipitate had a red colouration, however. The supernatant was removed and the precipitate was washed twice with water and twice with $\mathrm{MeOH}$ to remove impurities. The nanoparticles were designated as Au-1.

\subsection{Characterisation of the nanoparticles}

The nanoparticles produced thus were found to be insoluble in most of the solvents including water, $\mathrm{MeOH}$, dimethylsulfoxide etc. The precipitate was then sonicated in a bath sonicator at $60^{\circ} \mathrm{C}$ for $30 \mathrm{~min}$ in $1 \mathrm{M} \mathrm{NaOH}(5 \mathrm{ml})$. This resulted in the solubilisation of the particles and formation of a red solution. They were then characterised by UV-Vis spectroscopy on Shimadzu UV2100 spectrophotometer, to know the position of their surface plasmon band. For this, a $0.1 \mathrm{mg} / \mathrm{ml}$ solution of nanoparticles in aqueous $\mathrm{NaOH}$ was used. This showed a broad absorption in the 500-600 nm range having maxima at $517 \mathrm{~nm}$. We attempted dialysis of the above-mentioned suspension using a $12 \mathrm{kDa}$ dialysis membrane and using $\mathrm{pH} 9 \mathrm{NaOH}$ solution for dialysis. But this led to precipitation of the particles and they could not be re-suspended. This was not tried further. Electron microscopic analysis was done on JEOL JEM 200 CX electron microscope to investigate about the morphology and size distribution of the particles prepared. A dilute suspension of sample in aqueous sodium hydroxide as well as in water was dropcoated on a Formvar ${ }^{\mathrm{TM}}$ and carbon-coated copper grids. This was allowed to dry in air and then analysed at $120 \mathrm{kV}$ at magnifications of 68,000-80,000 times.

\section{Results and discussion}

Nanoparticles of noble metals are characterised by the presence of bright colours ascribed to the oscillations of the surface electron cloud of these particles. The collective oscillations of electrons of a nanoparticle upon interaction with light of suitable energy causes the nanoparticles to attain colour specific to particular metal. The frequency of oscillation is strongly dependent on the particle size, shape and aggregation. Larger particles show absorption that is more red-shifted as compared to the smaller ones. Similarly, nanoparticles close enough to interact electronically can give rise to electron 
oscillations that are collective to the aggregates. Thus, aggregates of nanoparticles have plasmon oscillations that become red-shifted as compared to the individual nanoparticles. This phenomenon holds tremendous promise in chemical and biological sensors. Using nanoparticles as reporters, visual sensing is possible as was shown by Mirkin et al. Keeping this in mind, $\mathbf{1}$ was synthesised which has a thiol-functionality at one end and metal-chelating iminodiacetic acid moiety at the other. It was surmised that the thiol moiety would bind to nascent particle and stabilise it. The iminodiacetic acid moiety would be available then for the metal chelation. But we observed that the particles formed were not stable and precipitated out of the reaction mixture. The precipitated material was sonicated with aqueous $\mathrm{NaOH}$. This led to the solubilisation of the precipitate and formation of a red colored solution. This was first studied by UV-Vis spectroscopy. As shown in figure 1, the solution showed a broad surface plasmon resonance at around $520 \mathrm{~nm}$ indicating particles of nanodimension. The plasmon band was broad and less prominent because of the polydispersity present in the sample, but its presence confirmed the existence of gold nanoparticles in the precipitate. We observed the sample under TEM and found this to be quite true. Figure 2 shows a transmission electron micrograph of the $\mathrm{NaOH}$ solution of nanoparticles. The particles in the sample were of 3-10 nm diameter. Analysis of the precipitated sample indicated that the particles were agglomerated together. As seen in figure 3, individual nanoparticles are seen but the particles form large aggregates. This most probably is due to the intermolecular hydrogen

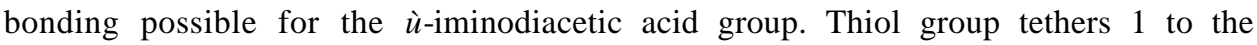
nanoparticle surface but the acid functionalities are free to form inter- and intra-particle hydrogen bonds. Inter-particle hydrogen bonding brings the particles closer and lead to their precipitation from the solution. The dense assemblies of nanoparticles show up as macroscopic precipitates. In fact, there has been numerous instances where the carboxylic acid moiety of the stabiliser leads to agglomeration/aggregation. ${ }^{18,19}$ Such assemblies are mediated by strong hydrogen bonds formed between the carboxylic acid moieties of the

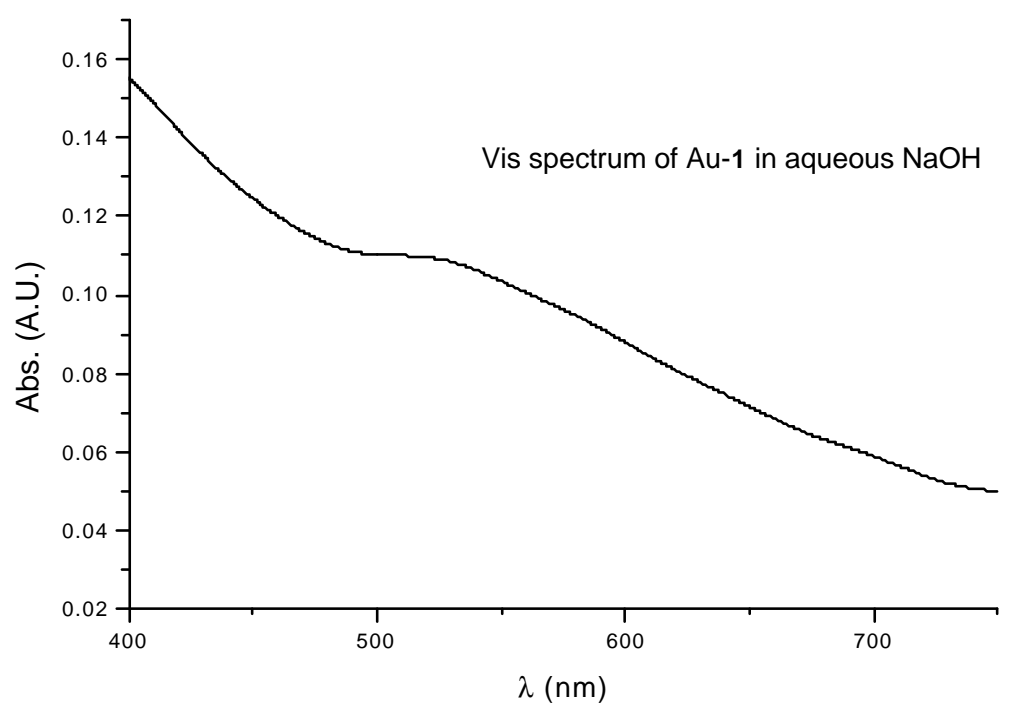

Figure 1. Visible range spectrum of Au-1 showing the surface plasmon band. 


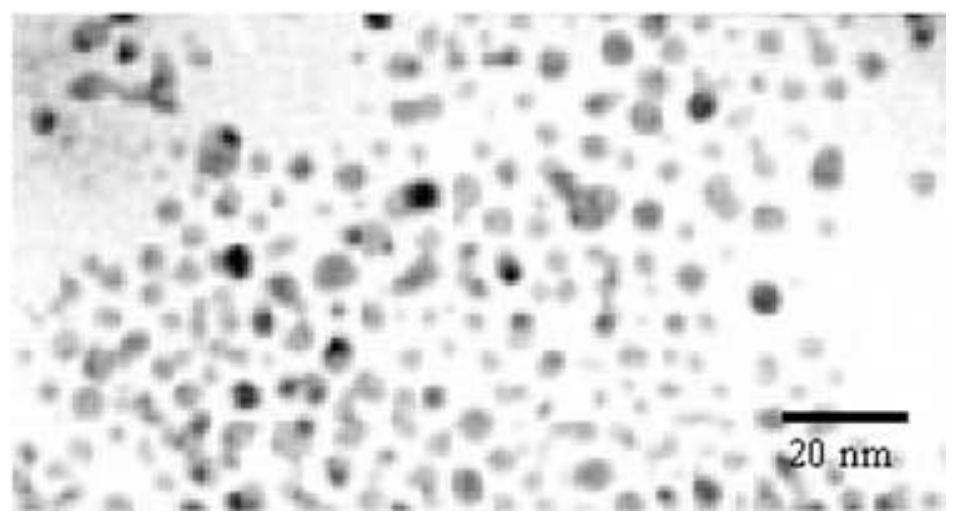

Figure 2. $\mathrm{Au}-1$ as $\mathrm{NaOH}$ solution $(\mathrm{pH} \sim 12)$.

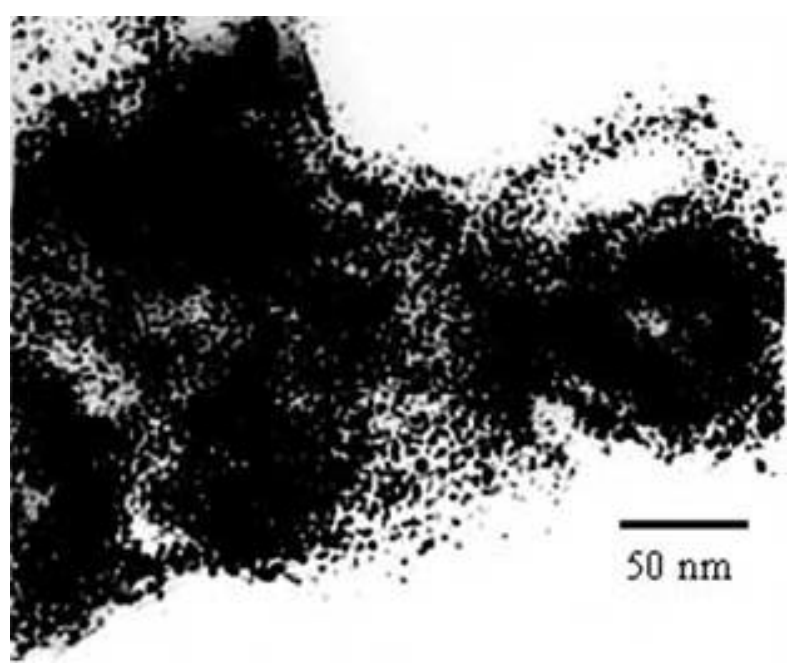

Figure 3. Dense nanoparticle aggregate formed in aqueous solution ( $\mathrm{pH}$ 6.5)

stabiliser. These are an important class of aggregates whose assembly is governed by non-covalent interactions. Similar non-covalent strategies of nanoparticle assembly have been explored by various groups. ${ }^{20-25}$ Murray et al reported the use of metal ions to form controlled and reversible aggregates of nanoparticles. ${ }^{26}$ The complexation of $\mathrm{Cu}^{2+}$ with the carboxylate moieties on the nanoparticle was utilised in this case to form the aggregates. The aggregation could be controlled by lowering the $\mathrm{pH}$ and by adjusting the quantity of $\mathrm{Cu}^{2+}$ added. The aggregates were re-dissolved using acetic acid. Such aggregates were utilised for the efficient quantized double-layer charging of the nanoparticulate films. $^{27}$

Hence, the nanoparticles synthesised in the present communication can have important applications in the fields of more efficient metal ion sensors as well as in formation of novel non-covalent nanoparticle aggregates. Further experiments are on to achieve these aims. 


\section{Conclusions}

In conclusion, nanoparticle-stabiliser molecule $\mathbf{1}$ was synthesised and characterised using various standard techniques like elemental analysis, FTIR and mass spectroscopy. This was then used to form nanoparticles of gold of small size-dispersion. These particles exhibited a tendency to agglomerate due to hydrogen bonding ability of the carboxylic acid moiety of the stabilizer 1. TEM analysis indicated the presence of close-packed aggregates in the sample that exhibited complete precipitation from the solution and reluctance to dissolution. Sonication in the presence of concentrated sodium hydroxide solution was required for the dissolution of the precipitate. These nanoparticles are expected to lead to more efficient sensing of the metals ions due to the presence of a strong metal-chelating moiety anchored to the nanoparticle surface. Studies are on to attempt the metal sensing by these nanoparticles as well as to gain further control over the aggregation properties of these nanoparticles.

\section{References}

1. Rao C N R and Cheetam A K 2001 J. Mater. Chem. 112887

2. Rao C N R, Kulkarni G U, Thomas P J and Edwards P P 2002 Chem. Eur. J. 829

3. Murphy C J and Coffer J L 2002 Appl. Spectroscopy 56 16A

4. Alvarez M M, Khoury J T, Schaaff T G, Shafigullin M N, Vezmar I and Whetten R L 1997 J. Phys. Chem. B101 3706

5. Link S and El-Sayed M A 1999 J. Phys. Chem. B103 4212

6. Link S and El-Sayed M A 1999 J. Phys. Chem. B103 8410

7. Brust M, Walker M, Bethell D, Schiffrin D J and Whyman R 1994 J. Chem. Soc., Chem. Commun. 801

8. Hostetler M J, Wingate J E, Zhong C J, Harris J E, Vachet R W, Clark M R, Londono J D, Green S J, Stokes J J, Wignall G D, Glish G L, Porter M D, Evans N D and Murray R W 1998 Langmuir 1417

9. Leff D V, Ohara P C, Heath J R and Gelbart W M 1995 J. Phys. Chem. 997036

10. Bhattacharya S and Srivastava A 2003 Langmuir 194439

11. Ahmadi T S, Wang Z L, Green T C, Henglein A and El-Sayed M A 1996 Science 281924

12. Nikoobakht B and El-Sayed M A 2003 Chem. Mater. 151957

13. Mou C-Y and Lin H-P 2000 Pure Appl. Chem. 72137

14. Malynych S and Chumanov G 2003 J. Am. Chem. Soc. 1242896

15. Reynolds R A III, Mirkin C A and Letsinger R L 2000 J. Am. Chem. Soc. 1223795

16. Lin S-Y, Liu S-W, Lin C-M and Chen C-H 2002 Anal. Chem. 74330

17. Brust M, Fink J, Bethell D, Schiffrin D J and Kiely C 1995 J. Chem. Soc., Chem. Commun. 1655

18. Li H, Luo J, Kariuki N N, Maye M M, Jones V W and Zhong C J 2003 Chem. Mater. 1529

19. Mandal S, Gole A, Lala N, Gonnade R, Ganvir V and Sastry M 2001 Langmuir 176262

20. Kulkarni G U, Thomas P J and Rao C N R 2002 Pure. Appl. Chem. 741581

21. Connolly S and Fitzmaurice D J 1999 Adv. Mater. 111202

22. Behrens S, Rahn K, Habicht W, Böhm K-J, Rösner H, Dinjus E and Unger E 2002 Adv. Mater. 141621

23. Alivisatos P A, Johnsson K P, Peng X, Wilson T E, Loweth C J, Bruchez Jr M P and Schultz P G 1996 Nature (London) 382609

24. Park S-J, Lazarides A A, Mirkin C A and Letsinger R L 2001 Angew. Chem. Int. Ed. 402909

25. Mann S, Shenton W, Li M, Connolly S and Fitzmaurice D 2000 Adv. Mater. 12147

26. Templeton A C, Zamborini F P, Weulfig W P and Murray R W 2000 Langmuir 166682

27. Zamborini F P and Murray R W $2000 \mathrm{~J}$. Am. Chem. Soc. 1224514 